\title{
Transcatheter arterial embolization for severe blunt liver injury in hemodynamically unstable patients: a 15-year retrospective study
}

Satoshi Tamura*, Takaaki Maruhashi, Fumie Kashimi, Yutaro Kurihara, Tomonari Masuda, Tasuku Hanajima, Yuichi Kataoka and Yasushi Asari

\begin{abstract}
Background: Transcatheter arterial embolization (TAE) is the first-line nonsurgical treatment for severe blunt liver injury in patients, whereas operative management (OM) is recommended for hemodynamically unstable patients. This study investigated the comparative efficacy of TAE in hemodynamically unstable patients who responded to initial infusion therapy.

Methods: This retrospective study enrolled patients with severe blunt liver injuries, which were of grades III-V according to the American Association for the Surgery of Trauma Organ Injury Scale (OIS). Patients who responded to initial infusion therapy underwent computed tomography to determine the treatment plan. A shock index $>1$, despite undergoing initial infusion therapy, was defined as hemodynamic instability. We compared the clinical outcomes and mortality rates between patients who received $\mathrm{OM}$ and those who underwent TAE.

Results: Sixty-two patients were included (eight and 54 who underwent OM and TAE, respectively; mean injury severity score, 26.6). The overall in-hospital mortality rate was $6 \%(13 \% \mathrm{OM}$ vs. $6 \% \mathrm{TAE}, p=0.50)$, and the hemodynamic instability was 35\% (88\% OM vs. 28\% TAE, $p<0.01)$. Hemodynamically unstable patients who underwent TAE had 7\% in-hospital mortality and 7\% clinical failure. Logistic regression analysis showed that the treatment choice was not a predictor of outcome, whereas hemodynamic instability was an independent predictor of intensive care unit stay $\geq 7$ days (odds ratio [OR], 3.80; $p=0.05)$ and massive blood transfusion $(\mathrm{OR}, 7.25 ; p=0.01$ ); OIS grades IV-V were predictors of complications (OR, 6.61; $p<0.01)$.

Conclusions: TAE in hemodynamically unstable patients who responded to initial infusion therapy to some extent has acceptable in-hospital mortality and clinical failure rates. Hemodynamic instability and OIS, but not treatment choice, affected the clinical outcomes.
\end{abstract}

Keywords: Hepatic trauma, Liver injury, Blunt trauma, Non-operative management, Angioembolization, Transcatheter arterial embolization, Interventional radiology

\footnotetext{
* Correspondence: tamusato1984@gmail.com

Department of Emergency and Critical Care Medicine, Kitasato University School of Medicine, 1-15-1, Kitasato, Minami-ku, Sagamihara, Kanagawa 252-0374, Japan
}

(c) The Author(s). 2021 Open Access This article is licensed under a Creative Commons Attribution 4.0 International License, which permits use, sharing, adaptation, distribution and reproduction in any medium or format, as long as you give appropriate credit to the original author(s) and the source, provide a link to the Creative Commons licence, and indicate if changes were made. The images or other third party material in this article are included in the article's Creative Commons licence, unless indicated otherwise in a credit line to the material. If material is not included in the article's Creative Commons licence and your intended use is not permitted by statutory regulation or exceeds the permitted use, you will need to obtain permission directly from the copyright holder. To view a copy of this licence, visit http://creativecommons.org/licenses/by/4.0/. The Creative Commons Public Domain Dedication waiver (http://creativecommons.org/publicdomain/zero/1.0/) applies to the data made available in this article, unless otherwise stated in a credit line to the data. 


\section{Background}

Nonoperative management (NOM) of blunt liver injury through transcatheter arterial embolization (TAE) is reportedly associated with a success rate of $80-97 \%$ when used with advanced techniques in interventional radiology (IR) [1]. In addition, guidelines recommend TAE as the first-line therapy in hemodynamically stable patients with blunt liver injury [2]. However, there are recommendations (Level of Evidence I) for laparotomy in patients who are hemodynamically unstable, and NOM should not be selected for the management of patients with hemodynamic instability [3]. A small case series reported that TAE could be useful for hemodynamically unstable patients in facilities that could have quick and accurate application of the procedure [4]; however, to date, there are no comparative studies of TAE and operative management $(\mathrm{OM})$ in hemodynamically unstable patients with liver injury.

Our institution has an IR-equipped emergency department, which facilitates a quick TAE; therefore, we attempted to perform TAE even in hemodynamically unstable patients with liver injury. This retrospective study covering a 15-year study period was conducted to determine whether TAE for severe blunt liver injury is associated with poorer prognosis in hemodynamically unstable patients. Moreover, we comparatively evaluated the differences in prognosis between TAE and OM.

\section{Methods}

\section{Study design and methodology}

This retrospective observational study reviewed the data of all patients with severe blunt liver injury (American Association for the Surgery of Trauma [AAST] grades III-V) who were treated at the Kitasato University Hospital Emergency and Critical Care Center between 2005 and 2019. We excluded patients with cardiac arrest on arrival. Regardless of age, all patients who received OM or TAE as initial treatment were included in this study. The OM and TAE groups included patients who underwent laparotomy for hemostasis and embolization for the treatment of severe blunt liver injury, respectively.

Our facility was the only regional trauma center serving a population of more than 1 million people, and our IR physicians were full-time staff at this center. Therefore, a 24-h IR facility was available at the study center.

\section{Clinical management and procedures}

All trauma patients received initial infusion therapy that consisted of a rapid 1-2-L infusion of crystalloid, albumin, and a blood transfusion. Patients in shock without elevated blood pressure received $\mathrm{OM}$ and underwent damage control surgery. When the clinical condition of the patient responded to initial infusion therapy, the patient underwent computed tomography (CT). When an intestinal injury was detected, the patient was transferred to the operating room (Op room) for OM. In patients with an extravascular leak of contrast on CT, TAE was performed in the IR room. A shock index $>1$, despite undergoing initial infusion therapy, was defined as hemodynamic instability. The shock index was defined by the ratio of the heart rate to the systolic blood pressure (SBP).

For embolization, the celiac artery was selected and accessed using a 5-Fr shepherd hook-type catheter (Hanaco Disposable Torque Catheter, Hanaco Medical Co., Saitama, Japan) or a 5-Fr cobra-type catheter (Torcon NB Advantage Catheter, Cook Japan, Tokyo, Japan). In pediatric patients, we used 4-Fr catheters. The hemostasis site was selected using a microcatheter, and a TAE was performed. In principle, we performed selective embolization; however, embolization from the right and left hepatic arteries or a more proximal site was acceptable when the patient was hemodynamically unstable. The embolic agents included gelatin sponge (through a pumping method) and coils or N-butyl cyanoacrylate, if there was an arterioportal shunt or coagulopathy, although the choice of the embolization material was determined at the IR physician's discretion.

\section{Data collection}

From electronic and paper medical records, we collected data on age, sex, mechanism of injury, vital signs at the time of visit, base excess, fibrinogen, Injury Severity Score (ISS), Trauma and Injury Severity Score (TRISS), time from arrival to $\mathrm{CT}$, time from arrival to admission into Op room/IR room, and operation/TAE time. The AAST classification [5] was used to grade patients based on intraoperative findings or retrospective examination of CT images. The following outcomes were compared between the two study groups: in-hospital mortality, number of units of blood transfusion within $24 \mathrm{~h}$ of admission, massive transfusions $(\geq 10$ units of red blood cells), length of intensive care unit (ICU) stay, hospitalization duration, complications, and clinical failure. Clinical failure was defined as patient death because of hemorrhage within $24 \mathrm{~h}$ of undergoing OM (OM group) and switching from TAE to OM (TAE group) owing to hemostatic challenges. Complications included biloma, hepatic ischemia, pseudoaneurysm, gallbladder necrosis, arterioportal shunt, and rebleeding, detected on $\mathrm{CT}$ at 1 week after admission. Patients were discharged or transferred to the other hospital when their condition was stabilized, and the follow-up period was defined as the duration of their stay in our hospital.

\section{Statistical analysis}

Statistical analyses were conducted using JMP ${ }^{\circ}$ (SAS Institute Inc., Cary, NC, USA), utilizing Student's t-test, 
the chi-square test, and the Wilcoxon rank sum test for comparisons between the OM and TAE groups and between the stable TAE and unstable TAE groups. Values of $p \leq 0.05$ indicated statistical significance. Pairwise deletion was performed when cases with missing data were used. Logistic regression analysis was conducted concerning the outcome and incorporated variables with $p<0.10$ and treatment choice as the variables on univariate analysis. Multivariate analysis was performed after organizing the cointegrated variables. The odds ratios (ORs) for each explanatory variable were calculated.

\section{Results}

During the study period, 92 cases of severe blunt liver injury (AAST grade $\geq$ III) were admitted, of which 30 chose NOM without TAE for initial treatment; therefore, 62 cases (eight and 54 who underwent $\mathrm{OM}$ and TAE, respectively) were included in the analysis dataset. Four $\mathrm{OM}$ cases were treated with damage control surgery without undergoing CT because of no response to the initial infusion therapy (Fig. 1). The median age in this study population was 29.5 (interquartile range [IQR] 20$54)$ years. The mechanisms of injury were traffic accidents $(n=50,81 \%)$, falls $(n=9,14 \%)$, and compression trauma $(n=3,5 \%)$; in this study population, the AAST grades were III $(n=36,58 \%)$, IV $(n=21,34 \%)$, and V $(n=5,8 \%)$. The mean ISS was $26.6 \pm 13.5$. There were four $(6 \%)$ deaths on admission, two (3\%) clinical failures, 18 (29\%) massive transfusions, and 34 (55\%) complications in total. The median ICU stay of patients in this study population was 5.5 (IQR 3-12) days.

The comparison of the OM and TAE groups showed significant differences in the mechanism of injury $(p=$ 0.02 ), blood pressure on arrival (OM 98.3 vs. TAE 125.9 $\mathrm{mmHg}, p=0.01$ ), Glasgow Coma Scale (GCS) score on arrival (OM 9.5 vs. TAE 15, $p=0.04$ ), base excess (OM -7.8 vs. TAE $-2.6, p<0.01$ ), ISS (OM 37.5 vs. TAE
24.9, $\mathrm{p}=0.01$ ), TRISS (OM 0.78 vs. TAE $0.96, p=0.05$ ), time from arrival to OM/TAE (OM 120.0 vs. TAE 76.1 min, $\mathrm{p}=0.02)$, time for OM or TAE (OM 146.5 vs. TAE $29.4 \mathrm{~min}, \mathrm{p}<0.01$ ), and hemodynamic instability (OM $88 \%$ vs. TAE $28 \%, \mathrm{p}<0.01$ ) (Table 1 ). Outcomes had significant differences in ICU stay duration (OM 20.5 vs. TAE 5 days, $\mathrm{p}=0.01)$ and massive transfusion $(\mathrm{OM} 75 \%$ vs. TAE $22 \%, p<0.01)$. Clinical failures included one case each in the OM (death because of hemorrhage) and TAE (hypotension during IR that revealed portal vein injury, with good postoperative outcome) groups. Deaths in the TAE group were caused by cancer, cerebral infarction, and sepsis.

In the TAE group, we further compared the subgroups of patients who were unstable and stable and found significant differences (Table 2) in the AAST grade $(p=$ 0.05 ), admission blood pressure (stable 133.0 vs. unstable $107.3 \mathrm{mmHg}, p<0.01$ ), base excess (stable -1.6 vs. unstable $-4.9, p<0.01$ ), ISS (stable 21.5 vs. unstable 33.9, $\mathrm{p}<0.01$ ), and TRISS (stable 0.98 vs. unstable 0.91, $p=0.02$ ). Outcomes had significant differences in length of ICU stay (stable 4 days vs. unstable 8 days, $\quad p<0.01$ ) and massive transfusion (stable $10 \%$ vs. unstable $53 \%, p<0.01$ ).

On univariate analyses of outcomes, the GCS score $(\mathrm{OR}, 0.65 ; p<0.01)$ and age (OR, 1.05; $\mathrm{p}=0.05)$ were significant factors for in-hospital mortality (Table 3 ). However, multivariate analysis with GCS score, age, and TAE as objective variables showed that the GCS score (OR, $0.48 ; p<0.01)$ and age $(\mathrm{OR}, 1.08 ; p=0.04)$ were significant factors accounting for multicollinearity (Table 4).

As observed on univariate analysis, the GCS score (OR, $0.83 ; \mathrm{p}=0.04)$, base excess $(\mathrm{OR}, 0.83 ; \mathrm{p}=0.04)$, ISS (OR, $1.08 ; p<0.01$ ), hemodynamic instability (OR, 7.03; $p<$ $0.01)$, and TAE (OR, $0.08 ; p<0.01)$ were significant factors for length of ICU stay $>7$ days (Table 3); however, in multivariate analysis adjusted for multicollinearity, only

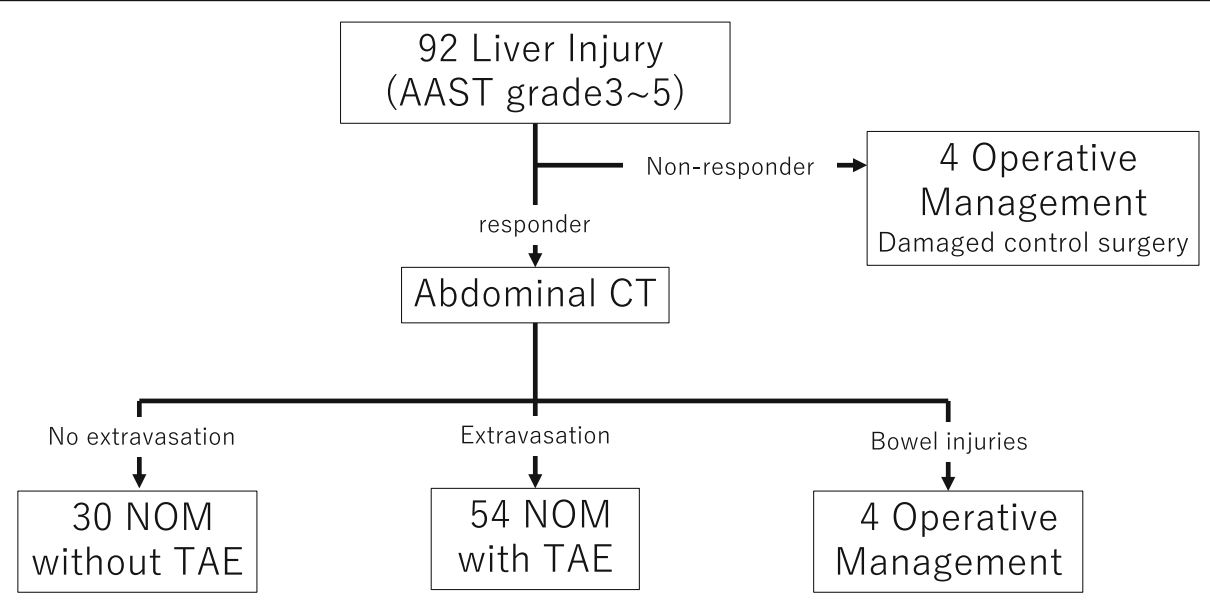

Fig. 1 Management algorithm for patients with liver injury. NOM, nonoperative management; TAE, transcatheter arterial embolization 
Table 1 Comparison between the operative management and transcatheter arterial embolization group

\begin{tabular}{|c|c|c|c|c|}
\hline & $\mathrm{OM}(n=8)$ & $\operatorname{TAE}(n=54)$ & $P$ value & All $(n=62)$ \\
\hline Mean age (IQR) & $35(20-41)$ & $28.5(20-55)$ & 1.00 & $29.5(20-54)$ \\
\hline Sex, (M/F) & $7 / 1$ & $42 / 12$ & 0.51 & $49 / 13$ \\
\hline Mechanism, n(\%) & & & 0.02 & \\
\hline trafic accident & $4(50 \%)$ & $46(85 \%)$ & & $50(81 \%)$ \\
\hline fall & $4(50 \%)$ & $5(9 \%)$ & & $9(14 \%)$ \\
\hline compression & $0(0 \%)$ & $3(6 \%)$ & & $3(5 \%)$ \\
\hline AAST grade of liber injury, n(\%) & & & 0.21 & \\
\hline gradelll & $3(38 \%)$ & $33(61 \%)$ & & $36(58 \%)$ \\
\hline grade IV & $3(38 \%)$ & $18(33 \%)$ & & $21(34 \%)$ \\
\hline grade $\mathrm{V}$ & $2(25 \%)$ & $3(6 \%)$ & & $5(8 \%)$ \\
\hline sBP on arrival (mean) & $98.3 \pm 30.2$ & $125.9 \pm 26.7$ & 0.01 & $122.7 \pm 28.2$ \\
\hline sBP on IR/Op room (mean) & $106.4 \pm 10.8$ & $134.8 \pm 3.9$ & 0.02 & $131.5 \pm 29.7$ \\
\hline RR on arrival (meanl) & $27.5 \pm 4.4$ & $25.2 \pm 6.3$ & 0.33 & $25.5 \pm 6.1$ \\
\hline GCS on arrival (median, IQR) & $9.5(6-15)$ & $15(14-15)$ & 0.04 & $15(13-15)$ \\
\hline Base Excess on arrical (mean) & $-7.8 \pm 4.4$ & $-2.6 \pm 3.6$ & $<0.01$ & $-3.1 \pm 4.0$ \\
\hline Fibrinogen on arrival (mean) & $215.3 \pm 105.1$ & $106.9 \pm 14.7$ & 0.47 & $241.1 \pm 106.3$ \\
\hline ISS (mean) & $37.5 \pm 16.9$ & $24.9 \pm 12.3$ & 0.01 & $26.6 \pm 13.5$ \\
\hline TRISS (median, IQR) & $0.78(0.21-0.97)$ & $0.96(0.86-0.99)$ & 0.05 & $0.95(0.85-0.98)$ \\
\hline Time from Door to start OM/TAE & $120.0 \pm 109.4$ & $76.1 \pm 34.9$ & 0.02 & $81.8 \pm 51.7$ \\
\hline Time for OM/TAE & $146.5 \pm 73.9$ & $52.5 \pm 5.2$ & $<0.01$ & $65.0 \pm 49.4$ \\
\hline Hemodynamically unstable ${ }^{a}$ & $7(88 \%)$ & $15(28 \%)$ & $<0.01$ & $22(35 \%)$ \\
\hline In-hospital mortality & $1(13 \%)$ & $3(6 \%)$ & 0.50 & $4(6 \%)$ \\
\hline Duration of ICU (median, IQR) & $20.5(10-35)$ & $5(3-9)$ & 0.01 & $5.5(3-12)$ \\
\hline Length of stay (median, IQR) & $62(27-128)$ & $23(15-35)$ & 0.03 & $26.5(16-43)$ \\
\hline \multicolumn{5}{|l|}{ Transfusion within first $24 \mathrm{~h}$} \\
\hline Units RBC (median, IQR) & $11(7-42)$ & $0(0-4.5)$ & $<0.01$ & $0(0-10)$ \\
\hline Units FFP (median, IQR) & $24(10.5-43)$ & $0(0-10.5)$ & $<0.01$ & $0(0-14)$ \\
\hline Units PIt (median, IQR) & $0(0-46)$ & $0(0-0)$ & 0.10 & $0(0-0)$ \\
\hline Massive transfusion ${ }^{\mathrm{b}}$ & $6(75 \%)$ & $12(22 \%)$ & $<0.01$ & $18(29 \%)$ \\
\hline Overall complication & 4 & 30 & 0.45 & 34 \\
\hline Biloma & $1(13 \%)$ & $12(22 \%)$ & 0.51 & $13(21 \%)$ \\
\hline Hepatic ischemia & $0(0 \%)$ & $7(13 \%)$ & 0.15 & $7(11 \%)$ \\
\hline Psuedoaneurysm & $0(0 \%)$ & $3(6 \%)$ & 0.36 & $3(5 \%)$ \\
\hline Gallbladder necrosis & $1(13 \%)$ & $1(2 \%)$ & 0.19 & $2(3 \%)$ \\
\hline AP shunt & $1(13 \%)$ & $5(10 \%)$ & 0.78 & $6(10 \%$ \\
\hline Rebleeding & $0(0 \%)$ & $1(2 \%)$ & 0.60 & $1(2 \%)$ \\
\hline Clinical failure & $1(13 \%)$ & $1(2 \%)$ & 0.19 & $2(3 \%)$ \\
\hline
\end{tabular}

${ }^{a}$ Hemodynamically unstable: A shock index $>1$, despite initial infusion therapy, was defined as hemodynamic instability

${ }^{\mathrm{b}}$ Massive transfusion: $\geq 10$ units of red blood cells

hemodynamic instability $(\mathrm{OR}, 3.80 ; p=0.05)$ showed significant associations (Table 4).

Concerning massive transfusion, the SBP on arrival (OR 0.97, $p<0.01$ ), GCS score (OR 0.79, $p=0.01$ ), base excess (OR 0.84, $p=0.02$ ), fibrinogen levels (OR, 0.99; $\mathrm{p}=0.01)$, ISS $\quad(\mathrm{OR}, 1.18 ; \mathrm{p}<0.01)$, hemodynamic instability (OR 15.8, $p<0.01$ ), and TAE (OR, $0.10 ; p<$ 0.01 ) were significant factors on univariate analysis (Table 3). However, only hemodynamic instability (OR, $7.25 ; \mathrm{p}=0.01)$ showed significant associations on multivariate analysis, accounting for multicollinearity (Table 4). Only severe liver injury (grades IV and V; OR, 6.61; 
Table 2 Comparison between unstable and stable patients who underwent transcatheter arterial embolization

\begin{tabular}{|c|c|c|c|}
\hline & Stable $(n=39)$ & Unstable $^{\mathrm{a}}(n=15)$ & $P$ value \\
\hline Mean age (IQR) & $35(20-56)$ & $24(17-32)$ & 0.08 \\
\hline Sex, $(M / F)$ & $30 / 9$ & $12 / 3$ & 0.81 \\
\hline Mechanism, n(\%) & & & 0.34 \\
\hline trafic accident & $34(87 \%)$ & $12(80 \%)$ & \\
\hline fall & $4(10 \%)$ & $1(7 \%)$ & \\
\hline compression & $1(3 \%)$ & $2(13 \%)$ & \\
\hline AAST grade of liber injury, n(\%) & & & 0.05 \\
\hline gradelll & $27(69 \%)$ & $6(40 \%)$ & \\
\hline grade IV & $11(28 \%)$ & $7(47 \%)$ & \\
\hline grade $\mathrm{V}$ & $1(3 \%)$ & $2(13 \%)$ & \\
\hline sBP on arrival (mean) & $133.0 \pm 3.9$ & $107.3 \pm 6.3$ & $<0.01$ \\
\hline sBP on IR/Op room (mean) & $143.6 \pm 4.0$ & $111.9 \pm 6.4$ & $<0.01$ \\
\hline RR on arrival (meanl) & $24.8 \pm 1.0$ & $26.4 \pm 1.6$ & 0.4 \\
\hline GCS on arrival (median, IQR) & $15(14-15)$ & $14(9-15)$ & 0.11 \\
\hline Base Excess on arrical (mean) & $-1.6 \pm 0.5$ & $-4.9 \pm 0.9$ & $<0.01$ \\
\hline Fibrinogen on arrival (mean) & $257.9 \pm 16.9$ & $209.1 \pm 28.3$ & 0.14 \\
\hline ISS (mean) & $21.5 \pm 1.8$ & $33.9 \pm 2.8$ & $<0.01$ \\
\hline TRISS (median, IQR) & $0.98(0.9-0.99)$ & $0.91(0.78-0.98)$ & 0.02 \\
\hline Time from Door to start TAE & $44.1 \pm 4.7$ & $53.3 \pm 7.8$ & 0.32 \\
\hline Time for TAE & $53.8 \pm 4.7$ & $48.7 \pm 8.2$ & 0.6 \\
\hline In-hospital mortality & $2(5 \%)$ & $1(7 \%)$ & 0.83 \\
\hline Duration of ICU (median, IQR) & $4(3-7)$ & $8(5-21)$ & $<0.01$ \\
\hline Length of stay (median, IQR) & $21(14-31)$ & $42(31-67)$ & $<0.01$ \\
\hline \multicolumn{4}{|l|}{ Transfusion within first24h } \\
\hline Units RBC (median, IQR) & $0(0-0)$ & $10(0-12)$ & $<0.01$ \\
\hline Units FFP (median, IQR) & $0(0-6)$ & $12(2-21)$ & $<0.01$ \\
\hline Units PIt (median, IQR) & $0(0-0)$ & $0(0-20)$ & 0.19 \\
\hline Massive transfusion ${ }^{\mathrm{b}}$ & $4(10 \%)$ & $8(53 \%)$ & $<0.01$ \\
\hline Overall complication & 21 & 8 & 0.83 \\
\hline Biloma & $7(18 \%)$ & $5(33 \%)$ & 0.24 \\
\hline Hepatic ischemia & $7(18 \%)$ & $0(0 \%)$ & 0.03 \\
\hline Psuedoaneurysm & $2(5 \%)$ & $1(7 \%)$ & 0.83 \\
\hline Gallbladder necrosis & $0(0 \%)$ & $1(7 \%)$ & 0.11 \\
\hline AP shunt & $5(13 \%)$ & $0(0 \%)$ & 0.06 \\
\hline Rebleeding & $0(0 \%)$ & $1(7 \%)$ & 0.11 \\
\hline Clinical failure & $0(0 \%)$ & $1(7 \%)$ & 0.11 \\
\hline
\end{tabular}

anstable: A shock index $>1$, despite initial infusion therapy, was defined as hemodynamic instability

${ }^{\mathrm{b}}$ Massive transfusion: $\geq 10$ units of red blood cells

$p<0.01)$ showed significant associations for the development of complications on univariate and multivariate analyses (Tables 3 and 4).

\section{Discussion}

The present study showed that in the treatment of severe blunt liver injury, the mortality rate was $6 \%$ in patients with hemodynamic instability who underwent TAE but responded to initial infusion therapy. TAE for hemodynamically unstable patients did not increase the mortality rate as compared with that for the stable group. A recent observational study from a trauma center reported a mortality rate of $3-8 \%$ for blunt liver injury and $15 \%$ for liver injuries of grades IV and V [6, 7], 
Table 3 univariate analyses of outcomes for intergroup comparison

\begin{tabular}{|c|c|c|c|c|c|c|c|c|}
\hline & \multicolumn{2}{|c|}{ In-hospital mortality } & \multicolumn{2}{|c|}{ Duration of $\mathrm{ICU} \geqq 7$ days } & \multicolumn{2}{|c|}{ Massive transfusion $^{\mathbf{b}}$} & \multicolumn{2}{|l|}{ Complication } \\
\hline & $\begin{array}{l}\text { Odds } \\
\text { ratio(95\%Cl) }\end{array}$ & $\begin{array}{l}\mathrm{p} \text { univariate } \\
\text { analysis }\end{array}$ & $\begin{array}{l}\text { Odds } \\
\text { ratio(95\%Cl) }\end{array}$ & $\begin{array}{l}p \text { univariate } \\
\text { analysis }\end{array}$ & $\begin{array}{l}\text { Odds } \\
\text { ratio(95\%Cl) }\end{array}$ & $\begin{array}{l}p \text { univariate } \\
\text { analysis }\end{array}$ & $\begin{array}{l}\text { Odds } \\
\text { ratio(95\%Cl) }\end{array}$ & $\begin{array}{l}\mathrm{p} \text { univariate } \\
\text { analysis }\end{array}$ \\
\hline Age & $1.05(0.89-1.01)$ & 0.05 & $1.00(0.79-1.02)$ & 0.83 & $0.99(0.98-1.04)$ & 0.61 & $0.99(0.98-1.04)$ & 0.33 \\
\hline Sex female & $1.28(0.12-13.41)$ & 0.84 & $1.99(0.54-7.37)$ & 0.29 & $0.90(0.24-3.41)$ & 0.88 & $0.59(0.16-2.19)$ & 0.42 \\
\hline $\begin{array}{l}\text { Severe liver injury } \\
\text { (gradelV,V) }\end{array}$ & $1.42(0.19-10.77)$ & 0.74 & $1.20(0.43-3.32)$ & 0.73 & $1.19(0.39-3.66)$ & 0.76 & $6.61(2.14-20.40)$ & $<0.01$ \\
\hline SBP (arrival) & $1.04(0.92-1.01)$ & 0.09 & $0.99(0.99-1.03)$ & 0.19 & $0.97(1.01-1.06)$ & $<0.01$ & $0.99(00.99-1.03)$ & 0.22 \\
\hline RR (arrival) & $0.91(0.91-1.31)$ & 0.33 & $1.06(0.86-1.03)$ & 0.16 & $1.05(0.87-1.05)$ & 0.32 & $1.00(0.92-1.09)$ & 0.98 \\
\hline GCS (arrival) & $0.65(1.13-2.09)$ & $<0.01$ & $0.83(0.99-1.47)$ & 0.04 & $0.79(1.05-1.54)$ & 0.01 & $0.99(0.85-1.20)$ & 0.90 \\
\hline Base Excess (arrival) & $0.97(0.78-1.37)$ & 0.81 & $0.77(1.09-1.55)$ & $<0.01$ & $0.84(1.02-1.39)$ & 0.02 & $1.00(0.87-1.14)$ & 0.99 \\
\hline Fibrinogen (arrival) & $1.00(0.99-1.01)$ & 0.86 & $1.00(0.998-1.01)$ & 0.11 & $0.99(1.00-1.02)$ & 0.01 & $1.00(0.99-1.00)$ & 0.84 \\
\hline ISS & $1.05(0.90-1.02)$ & 0.19 & $1.08(0.88-0.98)$ & $<0.01$ & $1.18(0.77-0.93)$ & $<0.01$ & $0.99(0.97-1.05)$ & 0.57 \\
\hline $\begin{array}{l}\text { Time from Door to } \\
\text { start OM/TAE }\end{array}$ & $0.98(0.98-1.07)$ & 0.19 & $1.01(0.98-1.00)$ & 0.09 & $1.01(0.98-1.00)$ & 0.28 & $1.00(0.99-1.01)$ & 0.84 \\
\hline Time for OM/TAE & $0.97(0.97-1.10)$ & 0.13 & $1.01(0.98-1.00)$ & 0.06 & $1.00(0.98-1.01)$ & 0.44 & $0.99(0.99-1.02)$ & 0.24 \\
\hline $\begin{array}{l}\text { Hemodynamicaly } \\
\text { unstable }\end{array}$ & $1.90(0.25-14.52)$ & 0.54 & $7.03(2.19-22.59)$ & $<0.01$ & $15.8(4.08-60.74)$ & $<0.01$ & $0.96(0.33-2.78)$ & 0.94 \\
\hline TAE & $0.41(0.04-4.53)$ & 0.50 & $0.08(0.00-0.73)$ & $<0.01$ & $0.10(0.02-0.53)$ & $<0.01$ & $2.23(0.41-12.05)$ & 0.33 \\
\hline
\end{tabular}

${ }^{a}$ Hemodynamically unstable: A shock index $>1$, despite initial infusion therapy, was defined as hemodynamic instability

${ }^{b}$ Massive transfusion: $\geq 10$ units of red blood cells

with comparable results. The choice of treatment was not a predictor of outcome; the GCS score on arrival was a predictor of in-hospital mortality, and hemodynamic instability was an independent predictor of length of ICU stay $\geq 7$ days and massive blood transfusion. AAST grades $\mathrm{IV}$ and $\mathrm{V}$ were predictors of complications.

It has been reported that under certain conditions, TAE for hemodynamically unstable patients with liver injury does not increase the mortality rates. Previous studies have shown that factors contributing to failed NOM include high ISS, need for massive transfusion, hypotension on hospital arrival, high AAST, and intraperitoneal contrast extravasation [8-10]; however, some controversy prevails because AAST has been reported to be unrelated to the NOM failure rate [11-13].

A cohort study of 3627 patients with severe blunt liver injury of AAST Grade IV or higher reported that SBP < $90 \mathrm{mmHg}$ was more likely to result in failed NOM (OR, 2.07) and that higher rates of NOM failure and mortality in hypotensive patients were associated with higher rates of NOM [13].

There are a few case reports of successful NOM with TAE for hemodynamically unstable patients [14-16]; however, a recent observational study reported that failure and mortality from NOM with TAE were independent of the hemodynamic status, with hemodynamic instability being defined as a case where the patient required rapid infusion or transfusion to maintain a $\mathrm{SBP}>90 \mathrm{mmHg}$ [4].

The success rate of TAE in patients with cardiovascular instability may depend on how quickly the procedure is initiated and completed. A historical cohort study [17] at the same institution reported that the introduction of a protocol wherein $\mathrm{CT}$ and TAE were performed within $30 \mathrm{~min}$ in cases of a response to the initial infusion therapy, even in cases where the patient was in shock at the time of admission, resulted in a decreased rate of $\mathrm{OM}$ without alterations in the failure or mortality rate. However, it was reported that only $6 \%$ of the NOM patients underwent TAE in facilities with IRs situated far from the trauma unit [18]. In this study, good access to IR and shortening of the duration from ER visit to TAE could have contributed to the results.

Patients who received TAE had fewer massive transfusions and shorter ICU stays than those who received $\mathrm{OM}$. These results are consistent with those from previous reports $[6,7]$ and suggested that TAE is less invasive than $\mathrm{OM}$ and thus, results in fewer transfusions and a faster recovery. However, in multivariate analysis, the hemodynamic status was the only predictor of ICU stay and massive transfusion, and may not depend on treatment. Regarding the complications, only AAST showed a correlation. This finding was consistent with reports, in which major complications after NOM occurred only in patients with AAST grade III or higher injuries [12]. Moreover, our findings showed that risk factors for complications in $453 \mathrm{NOM}$ cases were AAST grade IV (OR, 4.4) and V $(\mathrm{OR}, 12)$ injuries, independent of other factors [19]. The most common complications after TAE are hepatic necrosis, abscess, and biloma, according to a systematic review [20]. Complications are reported to occur in $70 \%$ of cases [21], suggesting that TAE may increase the complication rate [22]. There are reports that embolization should be undertaken more selectively than 


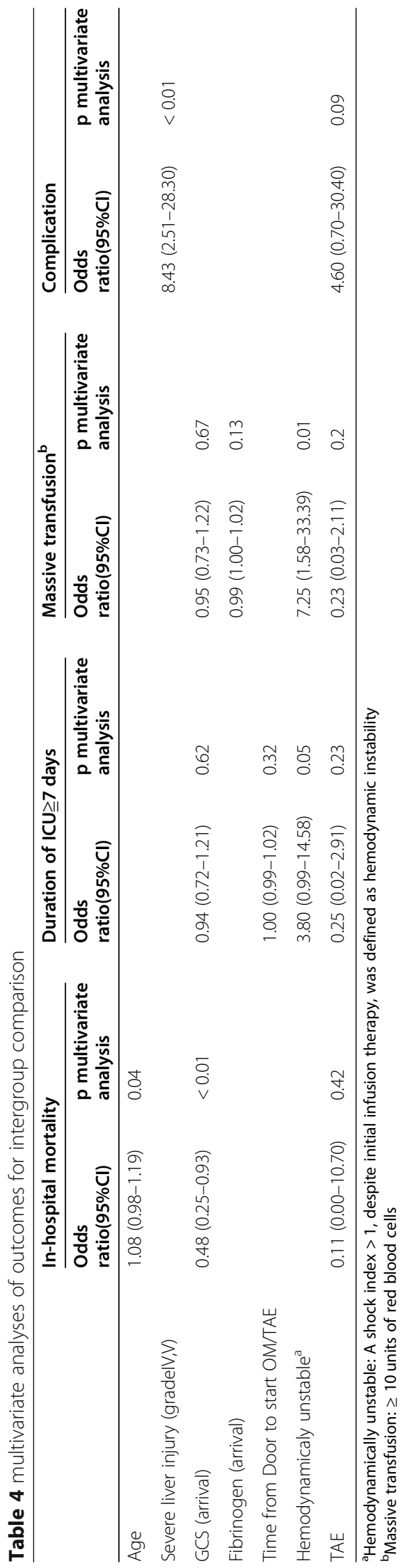


at the level of the proper hepatic artery to reduce complications [23, 24]. In the present study, we attempted to use selective embolization when the circulation dynamics permitted it.

There were more severe cases in the $\mathrm{OM}$ than in the TAE group because of the inability to perform CT when the patient was hemodynamically unstable and did not respond to initial infusion therapy. The mortality rate in severe blunt liver injury requiring $\mathrm{OM}$ is $>50 \%$ [25], and there are two ways to effectively utilize TAE in such cases. The first option is through resuscitative endovascular balloon occlusion of the aorta (REBOA), which has been reported to improve prognosis in severe trauma refractory to initial infusion therapy [26]. Thus, the inclusion of REBOA in our strategy may have further improved the prognosis in the TAE group. The other option is to effectively utilize TAE in a hybrid ER, where all examinations and treatments for trauma have been performed in a single station composed of a carbon-fiber fluoroscopic table with a self-propelled $\mathrm{C}$-arm combined with a sliding gantry CT scanner. The hybrid ER has been reported to increase the rate of IVR, shorten the time to treatment initiation, and improve the prognosis following the treatment for severe trauma [27], and it is also effective in shortening the time to treatment because TAE can be conducted when CT is completed.

The limitations of this study include its single-center, retrospective design. Moreover, the findings of this study may not be easily generalizable as the study center was a facility, which has immediate access to TAE. This study included a wide range of unstable patients, and those with severe hemodynamic instability that was nonresponsive to initial infusion therapy underwent surgery. Therefore, the number of patients with $\mathrm{OM}$ was small and could not be simply compared to that of patients with TAE, which vary greatly in severity. Future prospective studies are needed to specifically control the institutional and patient enrollment criteria for the validation of the preliminary findings from this research. In addition, the long-term prognosis was not considered in this study.

\section{Conclusion}

In centers with good access to TAE facilities, TAE could be an effective NOM option for hemodynamically unstable patients with severe blunt liver injury. Prospective and large-scale studies are needed to verify the specific criteria for treatment selection and for the application of these research findings in the clinical setting.

\section{Abbreviations}

AAST: American Association for the Surgery of Trauma; CT: Computed tomography; GCS: Glasgow Coma Scale; ICU: Intensive care unit; IQR: Interquartile range; IR: Interventional radiology; ISS: Injury Severity Score; NOM: Nonoperative management; OM: Operative management; Op room: Operating room; OR: Odds ratio; REBOA: Resuscitative endovascular balloon occlusion of the aorta; SBP: Systolic blood pressure;

TAE: Transcatheter arterial embolization; TRISS: Trauma and Injury Severity Score

\section{Acknowledgements}

This paper was edited by Editage (https://www.editage.jp). Statistical analysis was assisted by Satoko Tamura.

\section{Code availability}

Not applicable.

\section{Authors' contributions}

Study design, data acquisition, data analysis and interpretation, manuscript writing, manuscript review/critical revision. S.T., M.T., K.Y., and K.F. conducted study procedures (interventional) and Y.K., T.M., and T.H. undertook study procedures (surgical management). All authors have read and approved the final manuscript.

\section{Funding}

None.

\section{Availability of data and materials}

The datasets generated and analyzed during the current study are not publicly available because of protection of personal information but are available from the corresponding author on reasonable request.

\section{Declarations}

Ethics approval and consent to participate

This retrospective observational study involved human participants and was conducted in conformance with the principles of the Declaration of Helsinki and its amendments. The study protocol was approved by the Kitasato University Hospital Ethics Committee (approval no. B20-034), and the approving authority waived the need for informed consent for study participation because of the retrospective design of the study.

Consent for publication

Not applicable.

\section{Competing interests}

None declared.

Received: 15 December 2020 Accepted: 21 April 2021

Published online: 14 July 2021

\section{References}

1. Virdisa F, Recciab I, Di Saverioc S, Tugnolid G, Kwane SH, Kumarf J, et al. Clinical outcomes of primary arterial embolization in severe hepatic trauma: a systematic review. Diagn Interv Imaging. 2019;100(2):65-75. https://doi. org/10.1016/j.diii.2018.10.004.

2. Stassen NA, Bhullar I, Cheng JD, Crandall M, Friese R, Guillamondegui O, et al. Eastern Association for the Surgery of trauma. Nonoperative management of blunt hepatic injury: an eastern Association for the Surgery of trauma practice management guideline. J Trauma Acute Care Surg. 2012; 73(5 Suppl 4):S288-93. https://doi.org/10.1097/TA.0b013e318270160d.

3. Coccolini F, Montori G, Catena F, Di Saverio S, Biffl W, Moore EE, et al. Liver trauma: WSES position paper. World J Emerg Surg. 2015;10:39.

4. Koichi I, Shuhei U, Yoshiteru F, Masanao M. Nonoperative management of blunt liver injury in hemodynamically stable versus unstable patients: a retrospective study. Emerg Radiol. 2018;25(6):647-52.

5. Kozar RA, Crandall M, Shanmuganathan K, Zarzaur BL, Coburn M, Cribari C, et al. AAST patient assessment committee. Organ injury scaling 2018 update: spleen, liver, and kidney. J Trauma Acute Care Surg. 2018;85(6): 1119-22. https://doi.org/10.1097/TA.0000000000002058.

6. Gaski IA, Skattum J, Brooks A, Koyama T, Eken T, Naess PA, et al. Decreased mortality, laparotomy, and embolization rates for liver injuries during a 13year period in a major Scandinavian trauma center. Trauma Surgery \& Acute Care Open. 2018;3(1):1-6. 
7. Afifi I, Abayazeed S, El-Menyar A, Abdelrahman H, Peralta R, Al-Thani H. Blunt liver trauma: a descriptive analysis from a level I trauma center. BMC Surg. 2018;18(1):42. https://doi.org/10.1186/s12893-018-0369-4.

8. Huang YC, Wu SC, Fu CY, Chen YF, Chen RJ, Hsieh CH, et al. Tomographic findings are not always predictive of failed nonoperative management in blunt hepatic injury. Am J Surg. 2012;203(4):448-53. https://doi.org/10.1016/ j.amjsurg.2011.01.031.

9. Hsieh TM, Cheng Tsai T, Liang JL, Che LC. Non-operative management attempted for selective high grade blunt hepatosplenic trauma is a feasible strategy. World J Emerg Surg. 2014;9(1):51. https://doi.org/10.1186/17497922-9-51.

10. Fang JF, Wong YC, Lin BC, Hsu YP, Chen MF. The CT risk factors for the need of operative treatment in initially hemodynamically stable patients after blunt hepatic trauma. J Trauma. 2006;61(3):547-53. https://doi.org/10.1 097/01.ta.0000196571.12389.ee.

11. Hommes M, Navsaria PH, Schipper IB, Krige JE, Kahn D, Nicol AJ. Management of blunt liver trauma in 134 severely injured patients. Injury. 2015;46(5):837-42. https://doi.org/10.1016/j.injury.2014.11.019.

12. Brillantino A, lacobellis F, Festa P, Mottola A, Acampora C, Corvino F. Del Giudice, Lanza M, Armellino M, Niola R, Romano L, et al. non-operative management of blunt liver trauma: safety, efficacy and complications of a standardized treatment protocol. Bull Emerg Trauma. 2019;7(1):49-54. https://doi.org/10.29252/beat-070107.

13. Polanco PM, Brown JB, Puyana JC, Billiar TR, Peitzman AB, Sperry JL. The swinging pendulum: a national perspective of nonoperative management in severe blunt liver injury. J Trauma Acute Care Surg. 2013;75(4):590-5. https://doi.org/10.1097/TA.0b013e3182a53a3e.

14. Gregorio T, Francesco C, Carlo C, Andrea B, Alice P, Giovanni G, et al. "The best is nothing": non-operative management of hemodynamically stable grade V liver trauma. J Emerg Trauma Shock. 2015 Oct;8(4):239-40.

15. Nijhof HW, Willemssen FE, Jukema GN. Transcatheter arterial embolization in a hemodynamically unstable patient with grade IV blunt liver injury: is nonsurgical management an option? Emerg Radiol. 2006;12(3):111-5. https://doi.org/10.1007/s10140-005-0460-x.

16. Hagiwara A, Murata A, Matsuda T, Matsuda H, Shimazaki S. The usefulness of transcatheter arterial embolization for patients with blunt polytrauma showing transient response to fluid resuscitation. J Trauma. 2004;57(2):2716. https://doi.org/10.1097/01.TA.0000131198.79153.3C

17. Gaarder C, Naess PA, Eken T, Skaga NO, Pillgram-Larsen J, Klow NE, et al. Liver injuries--improved results with a formal protocol including angiography. Injury. 2007 Sep;38(9):1075-83. https://doi.org/10.1016/j.injury.2 007.02.001.

18. Bertens KA, Vogt KN, Hernandez-Alejandro R, Gray DK. Non-operative management of blunt hepatic trauma: does angioembolization have a major impact? Eur J Trauma Emerg Surg. 2015;41(1):81-6. https://doi.org/1 0.1007/s00068-014-0431-6.

19. Kozar RA, Moore FA, Cothren CC, Moore EE, Sena M, Bulger EM, et al. Risk factors for hepatic morbidity following nonoperative management: multicenter study. Arch Surg. 2006 May;141(5):451-8.

20. Green CS, Bulger EM, Kwan SW. Outcomes and complications of angioembolization for hepatic trauma: a systematic review of the literature. J Trauma Acute Care Surg. 2016;80(3):529-37. https://doi.org/10.1097/TA. 0000000000000942.

21. Letoublon C, Morra I, Chen Y, Monnin V, Voirin D, Arvieux C. Hepatic arterial embolization in the management of blunt hepatic trauma: indications and complications. J Trauma. 2011;70(5):1032-6 discussion 1036-7.

22. Sivrikoz E, Teixeira PG, Resnick S, Inaba K, Talving P, Demetriades D. Angiointervention: an independent predictor of survival in high-grade blunt liver injuries. Am J Surg. 2015;209(4):742-6. https://doi.org/10.1016/j.a mjsurg.2014.06.024.

23. Dabbs DN, Stein DM, Scalea TM. Major hepatic necrosis: a common complication after angioembolization for treatment of high-grade liver injuries. J Trauma. 2009;66(3):621-7 discussion 627-9.

24. Xu H, Jie L, Kejian S, Xiaojun H, Chengli L, Hongyi Z, et al. Selective angiographic embolization of blunt hepatic trauma reduces failure rate of nonoperative therapy and incidence of post-traumatic complications. Med Sci Monit. 2017;23:5522-33. https://doi.org/10.12 659/MSM.905115.

25. Di Saverio S, Catena F, Filicori F, Ansaloni L, Coccolini F, Keutgen XM, et al. Predictive factors of morbidity and mortality in grade IV and $V$ liver trauma undergoing perihepatic packing: single institution 14 years' experience at
European trauma Centre. Injury. 2012;43(9):1347-54. https://doi.org/10.1016/ j.injury.2012.01.003.

26. Otsuka H, Sato T, Sakurai K, Aoki H, Yamagiwa T, lizuka S, et al. Effect of resuscitative endovascular balloon occlusion of the aorta in hemodynamically unstable patients with multiple severe torso trauma: a retrospective study. World J Emerg Surg. 2018;13(1):49. https://doi.org/10.11 86/s13017-018-0210-5

27. Kinoshita T, Yamakawa K, Matsuda H, Yoshikawa Y, Wada D, Hamasaki T, et al. The survival benefit of a novel trauma workflow that includes immediate whole-body computed tomography, surgery, and interventional radiology, all in one trauma resuscitation room: a retrospective historical control study. Ann Surg. 2019;269(2):370-6. https://doi.org/10.1097/SLA. 0000000000002527

\section{Publisher's Note}

Springer Nature remains neutral with regard to jurisdictional claims in published maps and institutional affiliations.
Ready to submit your research? Choose BMC and benefit from:

- fast, convenient online submission

- thorough peer review by experienced researchers in your field

- rapid publication on acceptance

- support for research data, including large and complex data types

- gold Open Access which fosters wider collaboration and increased citations

- maximum visibility for your research: over $100 \mathrm{M}$ website views per year

At BMC, research is always in progress.

Learn more biomedcentral.com/submissions 